\title{
Prevalence and seasonal distribution of viral etiology of respiratory tract infections in inpatients and outpatients of the pediatric population: 10 year follow-up
}

Kübra Aykaç ${ }^{1}$, Eda Karadağ-Öncel ${ }^{1}$, Cihangül Bayhan ${ }^{1}$, Sevgen Tanır-Başaranoğlu ${ }^{1}$, Mustafa Şenol Akın², Yasemin Özsürekci ${ }^{1}$, Alpaslan Alp ${ }^{3}$, Ali Bülent Cengiz ${ }^{1}$, Ateş Kara' ${ }^{1}$, Mehmet Ceyhan ${ }^{1}$

Division of ${ }^{1}$ Pediatric Infectious Diseases ${ }^{2}$ Department of Pediatrics and ${ }^{3}$ Department of Microbiology and Clinical Microbiology, Hacettepe University Faculty of Medicine, Ankara, Turkey. E-mail: kubraklnc.kk@gmail.com

Received: 18th July 2017, Revised: 8th December 2017, 22nd January 2018, Accepted: 25th February 2018

SUMMARY: Aykaç K, Karadağ-Öncel E, Bayhan C, Tanır-Başaranoğlu S, Akın MŞ, Özsürekci Y, Alp A, Cengiz AB, Kara A, Ceyhan M. Prevalence and seasonal distribution of viral etiology of respiratory tract infections in inpatients and outpatients of the pediatric population: 10 year follow-up. Turk J Pediatr 2018; 60: 642-652.

The aim of this study was to investigate the prevalence and seasonal distribution of respiratory viruses in pediatric patients. Nasopharyngeal swab specimens, demographic and clinical information were collected from 1240 pediatric patients aged $<18$ years between 2006 and 2015 in Hacettepe University Children's Hospital. Multiplex RT-PCR (multiplex reverse transcriptase polymerase chain reaction) was performed to detect viral pathogens. A total of 1240 pediatric outpatients and inpatients who had been admitted to the hospital with symptoms of upper and lower respiratory tract infections (RTIs) were enrolled. Viruses were identified in 339 (27.3\%) of cases, with the leading three viruses being respiratory syncytial virus (RSV, 74/339; 21.8\%), human rhinovirus $(62 / 339 ; 18.3 \%)$, and multiple viruses $(56 / 339 ; 16.5 \%)$. Most of the patients were diagnosed with lower RTI $(264 / 339 ; 77.8 \%)$ and antibiotics were administered to three quarters of positive patients $(254 / 339$; $74.9 \%$ ). With an overall viral agent detection rate of $27.3 \%$, the findings of the present study suggest that other respiratory pathogens, whether viral or bacterial, may also lead to hospital visits due to respiratory tract symptoms in children.

Key words: respiratory infections, viruses, children.

Acute respiratory infections (ARIs) constitute a broad category of diseases that include infections of both the upper and lower respiratory tract, such as flu, acute pharyngitis, epiglottitis, bronchitis and pneumonia. ${ }^{1}$ According to the World Health Organization, respiratory tract infections account for the second leading cause of death among children, most of whom are under the age of five all around the world. ${ }^{2}$ Infants and young children (less than 5 years of age) have been estimated to have from three to eleven episodes of ARIs per year, with the highest incidence occurring during the first year of life. Even though many pathogens may cause ARIs, viruses are the most frequently implicated. ${ }^{1}$

Definition of the viruses which show seasonal characteristics are important in terms of vaccine studies, vaccination processes and the economic impacts of disease. ${ }^{3,4}$ Human rhinoviruses (hRV), parainfluenza viruses (PIV), respiratory syncytial viruses (RSV), enteroviruses (EV; coxackievirus, echovirus), adenoviruses (hAD), influenza viruses (IFV) 
are causative viral agents of ARIs ${ }^{5,6}$. In recent years we have seen new causative viruses such as human metapneumovirus (hMPV) (first identified in 2001), coronavirus associated with severe acute respiratory syndrome SARS (identified in 2003), human bocavirus (hBoV) (first identified in 2005) and two additional coronaviruses (NL63 and HKU1). ${ }^{7-9}$

In developing countries, RSV is the leading viral cause, having been identified in $15-40 \%$ of pneumonia or bronchiolitis cases in children admitted to hospital followed by influenza, parainfluenza, human metapneumovirus and adenovirus. $^{2}$

Although viruses are the most common causes of ARIs, main etiological diagnosis is often missed and unnecessary or inappropriate antibiotic use is seen in more than $50 \%$ of ARIs worldwide. ${ }^{10}$ This leads to the development of serious outcomes such as high resistance rates or multidrug resistance along with drug side effects in children infected with viruses. ${ }^{10,11}$ Turkey is a huge country, and its climate varies widely from region to region as well as seasonally. There has only been one study about viral respiratory tract infections carried out in Ankara which is the capital of Turkey although there were some studies from other cities. ${ }^{12-16}$ The aim of our study was to determine the prevalence and seasonal distribution of viruses in childhood respiratory infections in our center.

\section{Material and Methods}

The study was conducted at Hacettepe University Medical Faculty Ihsan Dogramaci's Child Hospital. Nasopharyngeal swab specimens, demographic and clinical informations were collected from 1240 pediatric patients aged $<18$ years between December 2006 and December 2015. There were 74 samples from 2006, 219 from 2007, 167 from 2008, 165 from 2009, 83 from 2010, 72 from 2013, 167 from 2014 and 271 from 2015. Clinical and demographic data of children with positive respiratory viral testing were analyzed retrospectively from our hospital records.

Duplicate specimens from the same patient (within one week of another specimen) were identified and excluded when the results were the same. If two samples were sent at the same time or within 3 days of one another, these were considered a single clinical episode if both were positive. A separate clinical episode was also assumed for patients with different viruses detected throughout their clinical course, independent of the time elapsed between sampling. Patients who died within 30 days after the diagnosis of infection were included in the mortality analysis. All samples received at the microbiology laboratory and tested for respiratory virus infections during the study period were eligible for inclusion. Samples that did not have test results because of failure of PCR or insufficient sampling, or had missing details of the patients were excluded.

Specimens were received from inpatient and outpatient children with ARI symptoms and were analyzed by multiplex RT-PCR (multiplex reverse transcriptase polymerase chain reaction) to detect viral pathogens. We tested samples for eight (IFV A-B, PIV 1-2-3, hAD, RSV, $\mathrm{CoV}$ ) viruses between 2006 and 2008. EV, hRV, hBoV, CoV 229/NL63 and CoV OC43/ HKU1 were added to the test in 2008. After 2014 we started to test 16 viruses in total adding RSV A, RSV B. Nucleic acid isolation was performed by Gene All Ribospin vRD II Isolation Kit, Seoul, Korea. Real time PCR method was carried out by Seegene RV16 Detection Kit, Seoul, Korea.

Lower respiratory tract infection (LRTI) was defined as one or more of the following clinical findings: hypoxia (<95\%), age-related tachypnea, signs of respiratory distress (retractions, nasal flaring, abdominal breathing) or abnormal breath sounds (wheezing, prolonged expiratory phase, or crackles) obtained by auscultation. ${ }^{17}$ Upper respiratory tract infection (URTI) was defined as nasal congestion, rhinorrhea, cough, and/or fever without associated wheezing or dyspnea. ${ }^{18}$

Acute respiratory failure (ARF) is a common medical emergency in children. It is defined as the inability to provide $\mathrm{O}_{2}$ and remove $\mathrm{CO}_{2}$ at a rate that meets metabolic demands. Chronic respiratory failure describes chronic respiratory processes requiring home oxygen or ventilator support (mechanical ventilator or nasal BiPAP), or having baseline $\mathrm{SaO}_{2}<88 \%$ on room air or $\mathrm{pCO}_{2}>50$ with a normal $\mathrm{pH} .{ }^{19}$

The investigation was reviewed and approved by the ethical committee of Hacettepe University (no:GO 17/88-27). Informed consent was obtained from all individual participants 


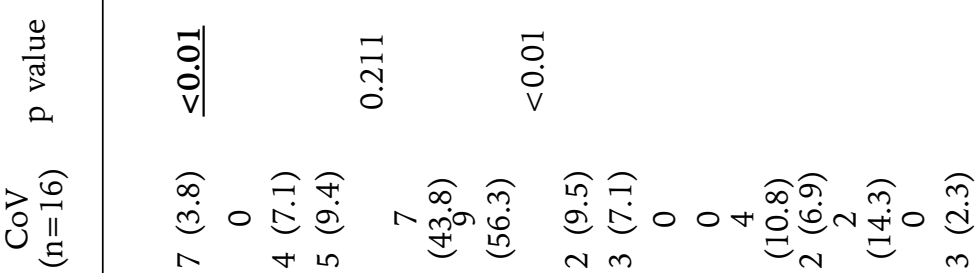

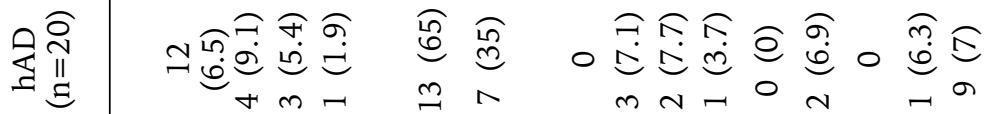

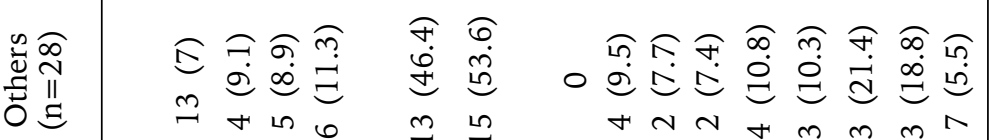

尼昰

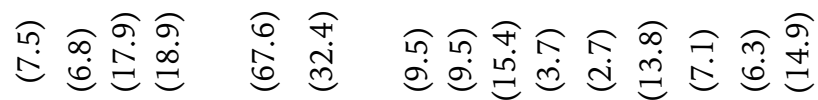

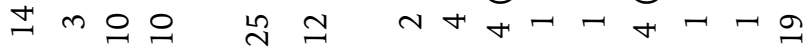

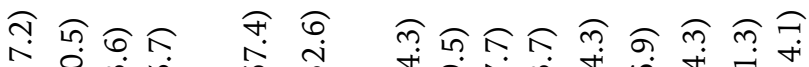
$\gtrless \stackrel{0}{\stackrel{0}{1}}$

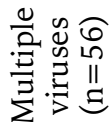
त्d $\sqrt[0]{\infty}$ in

तैa $n$ m

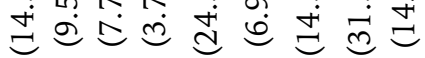
$m+n-a n d$ in

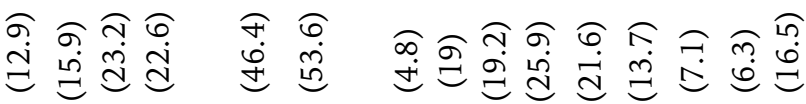

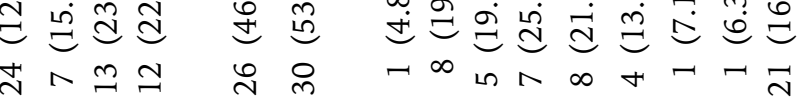

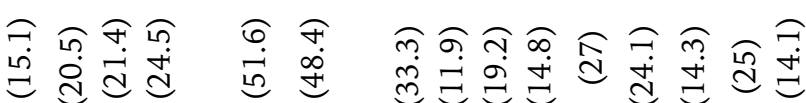

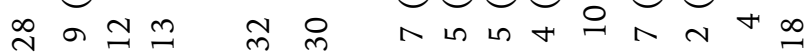
突蛋

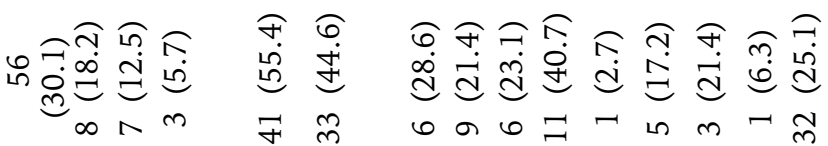

㺃莺 苞: 常 垔

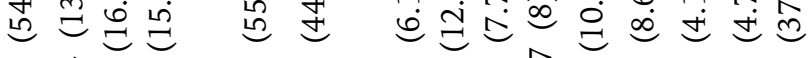

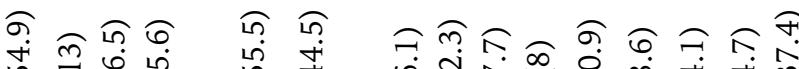

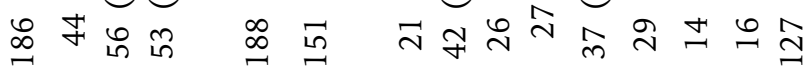

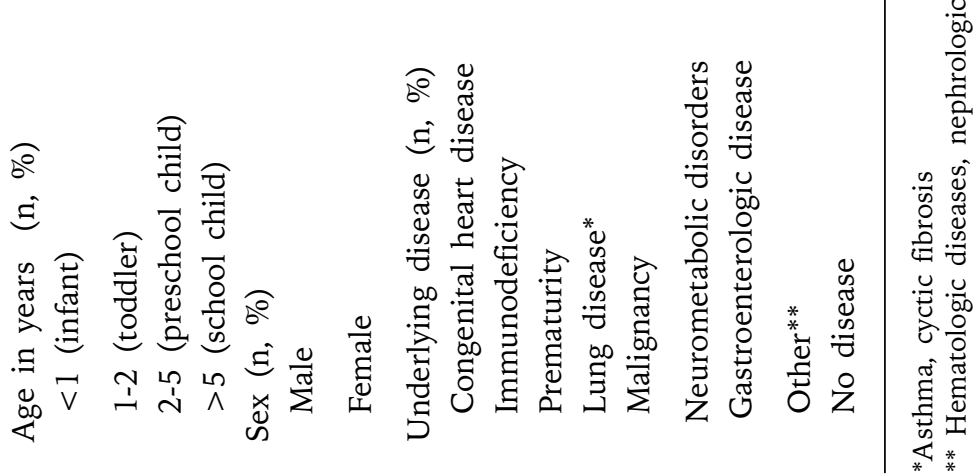


included in the study.

\section{Statistical Analysis}

Statistical analyses were analyzed with IBM SPSS for Windows version 20.0 (Chicago, IL). Values for numerical variables were provided as median (minimum-maximum) or mean \pm standard deviation, depending on the normality of distribution. Categorial variables were given as numbers and total percentages. For numerical variables, two-group comparisons were made using the Mann-Whitney U-test, whereas the Kruskal-Wallis test with Corover post hoc analysis was preferred for multiple comparisons. Comparisons between groups for categorical variables were made using the Chi-square $\left(x^{2}\right)$ test. Statistical significance was defined as $\mathrm{p}$ values less than 0.05 .

\section{Results}

During a ten-year follow up period, 1240 clinical respiratory specimens were analyzed. Of these, $901(72.6 \%)$ had no respiratory viruses detected and 339 (27.3\%) specimens had at least one respiratory virus detected. In this study 40 $(11.8 \%)$ of the patients were outpatients and $299(88.2 \%)$ of them were inpatients.

Bacterial blood cultures were received from $192(56.6 \%)$ patients. We detected bacteria from blood culture in $18(9.3 \%)$ patients. Frequent bacterial agents were Klebsiella pneumonia $(\mathrm{n}=3)$, Staphylococcus hominis $(\mathrm{n}=3)$,

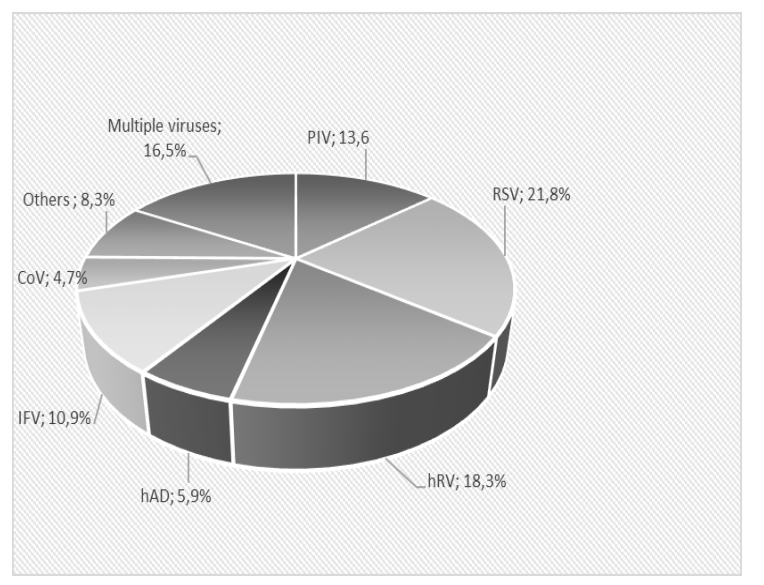

Fig. 1. Distribution of viruses

Human rhinoviruses (hRV), parainfluenza viruses (PIV), respiratory syncytial viruses (RSV), adenoviruses (hAD), influenza viruses (IFV), coronavirus (CoV)

Others: metapneumovirus, enteroviruses, bocavirus
Streptococcus pneumonia $(\mathrm{n}=2)$, Staphylococcus epidermidis $(\mathrm{n}=2)$.

\section{Demographic and Clinical Characteristics}

With regard to the age distribution of the total 339 patients, $186(54.9 \%)$ patients were aged $<1$ year, 44 patients $(13 \%)$ were aged between 1 and 2 years, 56 patients (15.6\%) were between 2 and 5 years and 53 patients $(15.6 \%)$ were $>5$ years, infants, toddlers, preschool and school aged children, respectively. All the detection rates of the different viruses were found to be significantly associated with the age groups $(p<0.01)$. Demographic and clinical characteristics of patients and each type of virus are shown in Table I.

A positive viral diagnosis was obtained in $339 / 1240(27.3 \%)$ patients. The detection rates of viruses in males and females were 188 $(55.5 \%)$ and 151 (44.5\%), respectively. The predominant virus was RSV, with a detection rate of $21.8(74 / 339)$. The viruses ranking second to eight were hRV, multiple viruses, PIV, IFV, others (hMPV, enteroviruses, bocavirus), hAD and CoV, with detection rates of $18.3 \%$, $16.5 \%, 13.6 \%, 10.9 \%, 8.3 \%, 5.9 \%$ and $4.7 \%$, respectively (Fig. 1).

The infant group had the highest percentage in total number of positive specimens (54.9\%). RSV, PIV and hRV were found most frequently in this group. Thirty-one $(30.1 \%)$ patients were RSV positive. PIV and hRV were found most frequently in toddlers, with a $20.5 \%$ rate for each virus. In the preschool child group multiple viruses and hRV were mostly detected with $23.2 \%$ and $21.4 \%$, respectively. Finally hRV $(24.5 \%)$ was seen to be the most predominant virus in the over 5 years group. Distribution of age and virus types are shown in Figure 2.

Cough $(78.5 \%)$, fever $(62.2 \%)$ and fatigue $(27.7 \%)$ were the most common clinical findings in patients. Both dyspnea and chest pain were not seen in patients with RSV and IFV $(p=0.01$ and $p=0.02)$. In terms of physical examination rales $(50.7 \%)$ and tachypnea $(86.6 \%)$ were common in patients. Tachypnea was seen in significantly lower rate in patients with hRV infection $(\mathrm{p}=0.02)$.

Acute respiratory failure rate was $64.6 \%$ and chronic respiratory failure rate was $17.5 \%$ on addmission. Patients with other viruses 


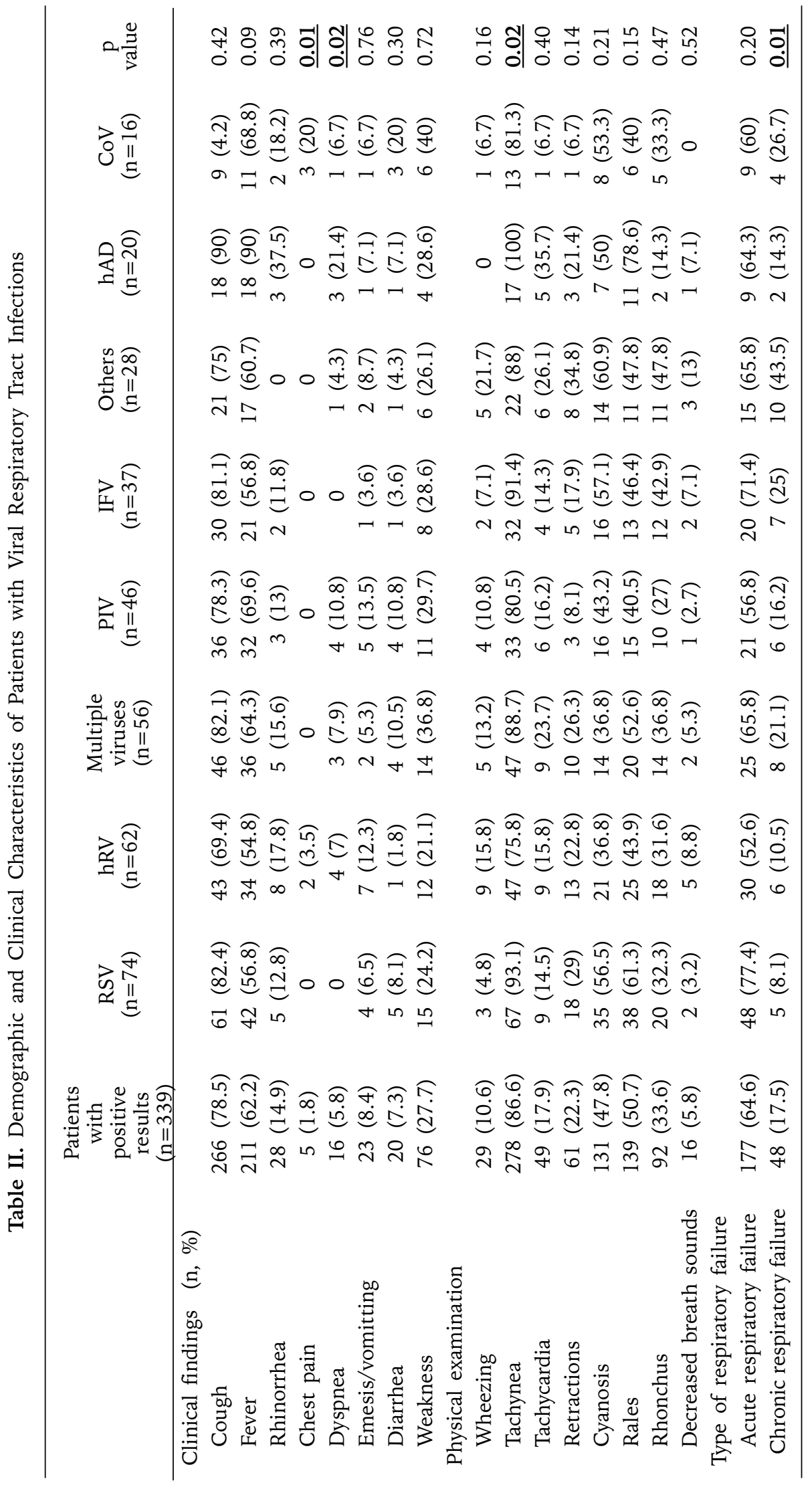




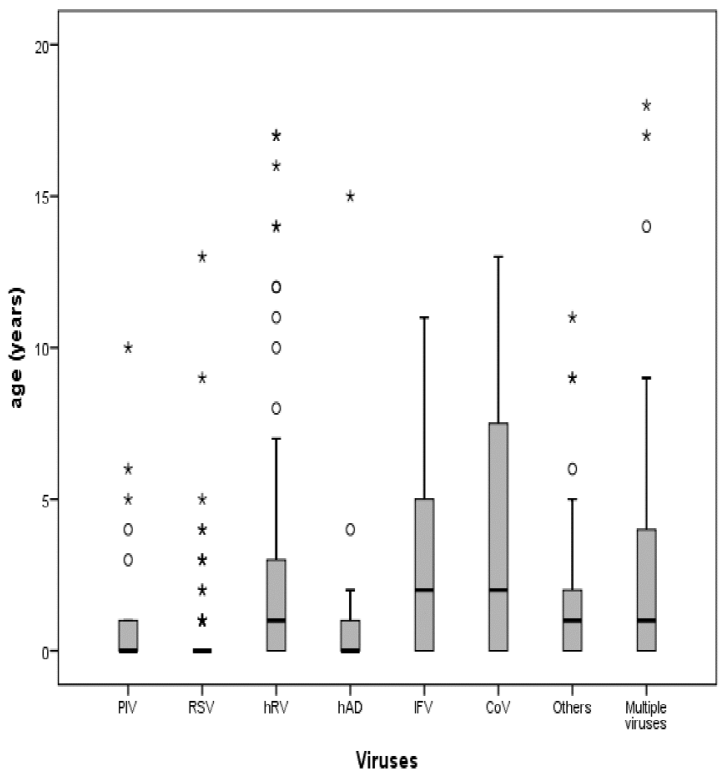

Fig. 2. Distribution of ages and viruses types Human rhinoviruses (hRV), parainfluenza viruses (PIV), respiratory syncytial viruses (RSV), adenoviruses (hAD), influenza viruses (IFV), coronavirus (CoV)

Others: metapneumovirus, enteroviruses, bocavirus

infections had significantly higher rate of having chronic respiratory failure on addmission.

The median blood leukocyte count of patients was $9,600 / \mathrm{mm}^{3}$ (min-max; 100-48,000). The median C-reactive protein (CRP) level was 0.4 $\mathrm{mg} / \mathrm{dl}$ (min-max; 0.1-29.6). The blood leukocyte count and CRP in ARIs were similar among different viruses. Leukopenia were seen in some patients with RSV, hRV, multiple viruses, PIV, IFV and hAD infections contrast in $\mathrm{CoV}$ and other viral infections were not seen.

\section{Seasonality}

Most viral respiratory tract infection tests were carried out during winter $(468,37.7 \%)$ and spring $(309,24.6 \%)$, compared with autumn $(268,21.6 \%)$ and summer $(195,15.7 \%)$. In general, common respiratory viruses were detected positive more often in winter (151, $44.5 \%)$ and spring $(98,28.9 \%)$ than autumn $(58,17.1 \%)$ and summer $(32,9.4 \%)(p<0.01)$. The highest positivity rate was obtained in January $(54,15.9 \%)$, and the lowest in July (9, $2.6 \%$ ). Monthly distribution and detection rates of ARIs in our cases can be seen in Figure 3.

Regarding the distribution of respiratory viruses by seasons and months, RSV (52, 34.4\%), hRV $(25,16.6 \%)$ and IFV $(20,13.2 \%)$ were mostly detected in winter. RSV was most detected in January and was not detected in June and October. HRV $(23,39.7 \%)$ and PIV was generally seen in autumn $(14,24.1 \%)$. PIV $(34.3 \%)$ and hAV (12.5\%) was especially seen in summer $(4,12.5 \%)$. Multiple viruses $(24,24.5 \%)$ and RSV $(19,19.4)$ were generally detected in spring.

\section{Clinical Features}

In terms of underlying disease 127 (37.4\%) patients had no disease and were healthy, as well as 42 (12.3\%), 37 (10.9\%), 29 (8.6\%), $27(8 \%), 21(6.1 \%)$ and $26(7.7 \%)$ had immunodeficiency (primary or secondary), malignancy, neurometabolic disease, lung disease (asthma, cyctic fibrosis), congenital heart disease and prematurity, respectively. There was statistical significance among the underlying disease $(\mathrm{p} \leq 0.01)$. RSV was detected most in healthy children (43.2\%), lung diseases (14.8\%) and immunodeficiency (12.1\%). HRV was frequently seen in patients with malignancy $(16.1 \%)$, in congenital heart disease $(11.2 \%)$ and neurometabolic disease (11.2\%) (Table II). The common clinical diagnosis was LRTI (264; $77.8 \%$ ) followed by URTI (64; $24.2 \%)$. Most patients with lower RTI had RSV $(64 ; 18.8 \%)$ and with URTI had hRV $(14 ; 21.8 \%)$ (Table III). In total seven patients died $(7 / 339,2 \%)$ and hAV $(n=2), \operatorname{CoV}(n=1)$, multiple viruses $(n=1)$,

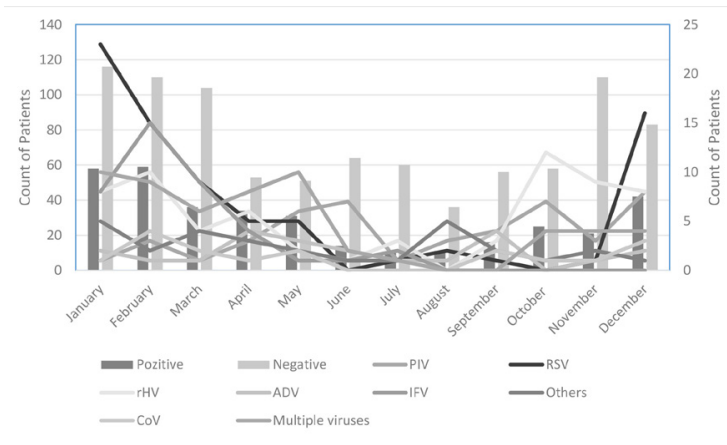

Fig. 3. Monthly distribution and detection rates of ARIs in cases

Human rhinoviruses (hRV), parainfluenza viruses (PIV), respiratory syncytial viruses (RSV), adenoviruses (hAD), influenza viruses (IFV), coronavirus (CoV)

Others: metapneumovirus, enteroviruses, bocavirus 


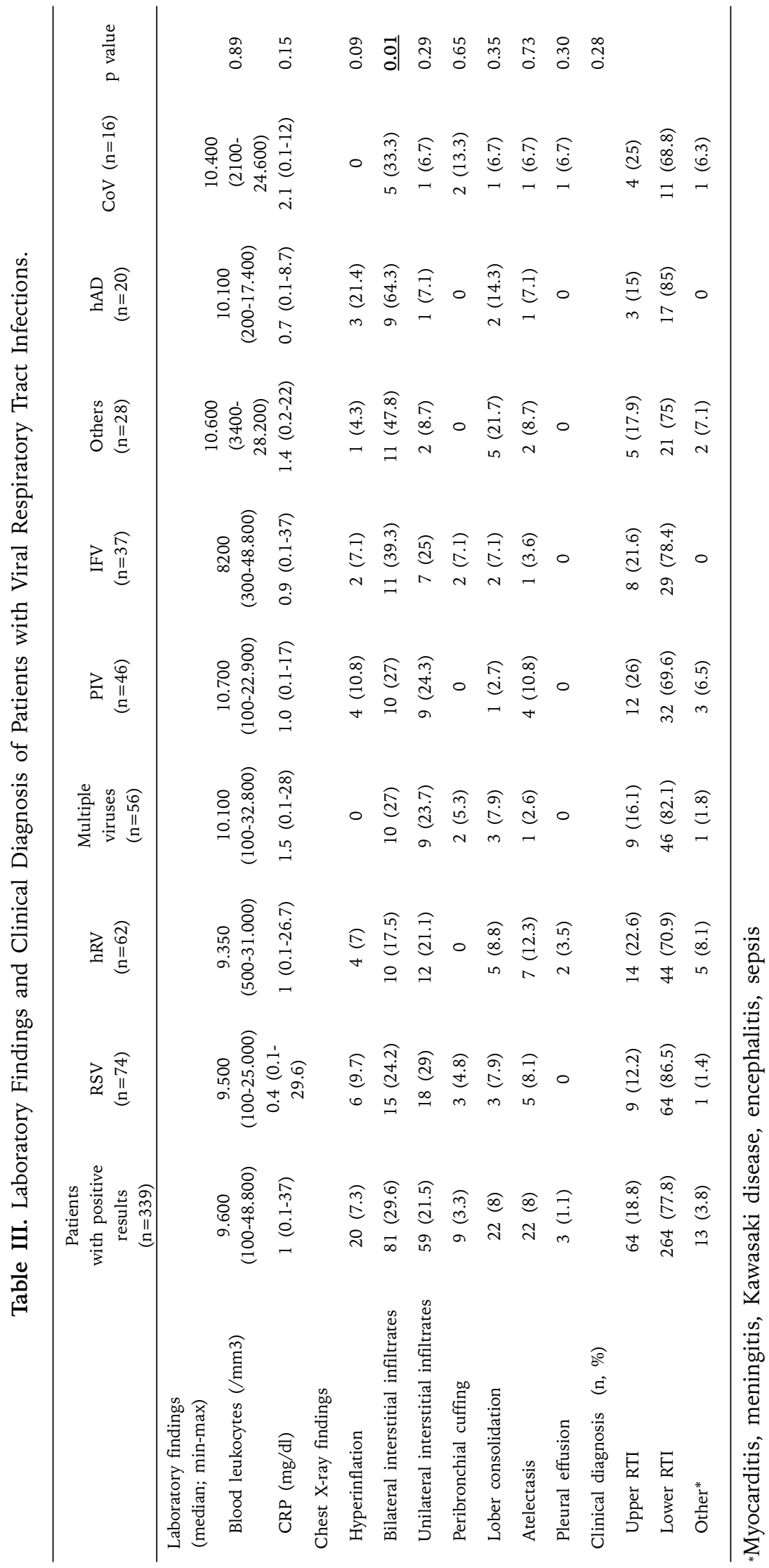


$\operatorname{IFV}(n=1), \operatorname{hRV}(n=1)$ and hMPV $(n=1)$ infections were detected in these patients. Patients who had hMPV, hRV and multiple viruses had Stenotrophomonas maltophilia, Rothia mucilaginosa, Klebsiella pneumonia bacteremia respectively in the same time. Three of them were under one year of age, three of them were over five year of age. Forty-two (12.3\%) patients had immunodeficiency as the most observed underlying disease and four of them (9.5\%) died after having been infected with hAD $(n=2)$, hRV $(n=1)$ and multiple viruses $(n=1)$. The most common virus causing mortality was hAD $(n=2)$. One of them was a school age child the others were infants. There were no mortalities among our nine immune deficiency patients with RSV infection.

Totally $299(88.2 \%)$ patients were hospitalized and $40(11.8 \%)$ patients were treated as outpatient. RSV (95.6\%) and CoV (93.8\%) were the common viruses infections that need to hospitalization. Overall there were 56 patients with multiple viral infection and $46(82.1 \%)$ of these were hospitalized, two of them were staying in the pediatric intensive care unit (PICU), only $10(17.9 \%)$ of them were inpatients.

Antibiotics were administered to three quarters of positive patients $(254 / 339 ; 74.9 \%)$ and antiviral (oseltamivir) treatment was used in $21(6.1 \%)$ patients.

\section{Discussion}

In this study, we completed an analysis of the viral etiology and clinical features of inpatient and outpatient children admitted to our tertiary care hospital. We evaluated the prevalence of the most frequent respiratory viruses based on a retrospective analysis of ten consecutive years' data. The overall detection rate in our study was $339(27.3 \%)$. It was lower than that recently reported in Turkey. The positivity rate reported varied from 38.0 to $40.3 \%$ depending on different areas, study design and virus analysis methods. ${ }^{12,}$ 20, 21

We found that RSV was the most frequent virus in the population with ARIs in our study population. Our result is compatible with those of other studies in which RSV ranks as the most frequent virus in the pediatric population along with ARIs. ${ }^{22,23}$ RSV was detected most in patients with lung disease, immunodeficiency and healthy children. Children with lung disease, especially prematures, are considered to be more susceptible to RSV infection, with resultant increased mortality and morbidity. Leung et al. ${ }^{24}$ indicated lung disease was the only risk factor for the duration of pediatric intensive care admission in the child population with RSV infection. Additionally severe RSV infection may alter the lung environment and lead to prolonged lung dysfunction long after the infection has been resolved. ${ }^{25}$ There were no fatalities among our study population, including patients with lung disease and immunodeficiency, however we had only 20 patients with RSV infection in these two disease group. There should be larger population studies to understand the significance of RSV infection in patients with immunodeficiency and lung disease.

The age distribution in this hospital-based study indicated that infants were more likely to be infected by RSV and PIV, toddlers with hRV and PIV, preschool and school aged children with hRV and multiple viruses. Previous studies had also indicated that RSV was generally seen in infants especially in the first years of life. ${ }^{11}$, 22, 26 In our other study between December 2011 and April 2012, RSV was significantly more common in infants in the outpatient population. ${ }^{16}$ Most studies have indicated that RSV infection rates are different between outpatients and inpatients. ${ }^{27,28}$ However only prematurity and being of a young age were detected as risk factors for hospitalization. ${ }^{28,29}$ Based on our findings, we have shown that RSV was most common among the inpatient population. In this study $40(11.8 \%)$ of the patients were outpatients and $299(88.2 \%)$ of them were inpatients. However we have not be able to perform viral respiratory tests on outpatients since 2009. Studies about viral etiology of respiratory disease are important for clinicians and also patients due to decisions about medication and appropriate public health strategies. Turkey and the other countries may affect the Health Minister's policy with such clinical and laboratory testing studies.

Although in this study 42 (12.3\%) of patients had immunodeficiency as the most obvious underlying disease and four (9.5\%) of them died after having been infected with hAD $(n=2)$, hRV $(n=1)$ and multiple viruses $(n=1)$. 
Asner et al. ${ }^{30}$ showed that immunodeficiency is a significant predictor of clinical disease severity among inpatients with RSV infection. However there were no mortalities among our nine immune deficiency patients with RSV infection. Totally seven patients died $(7 / 339,2 \%)$. In our study the most common virus that led to mortality was hAD. Two patients died after hAD infections. Both of them had immunodeficiency diseases. It has been reported in literature that hAD takes advantage of the impaired immunological response and infections develop, which leads to high morbidity or even mortality in these patients. $^{31}$

HRV was mostly seen in patients with malignancy, congenital heart disease, neurometabolic disease and healthy patients. HRV is common cause of URTI in hematologic malignancy patients in the literature, Jacobs et al. ${ }^{32}$ investigated hRV infections in hematologic malignancy and suggested that hRV are associated with LRTI in patients with such malignancy.

Overall, there were 56 patients with multiple viral infections and $46(82.1 \%)$ of them were hospitalized, two of them were followed up in PICU, 10 (17.9\%) were followed as outpatient Martínez-Roig et al. ${ }^{33}$ indicated that an inverse relationship was found between the number of viruses detected with a need for oxygen therapy and hospitalization period. However, it has been hypothesized that multiple viral infections may be associated with higher fever, longer durations of hospital stay, more frequent use of antibiotics and increased risk of requiring intensive care in a hospital-based study ${ }^{34}$. Richard et al. ${ }^{35}$ showed that co-infections such as RSV plus hRV may lead to a more severe clinical course of disease in infants with bronchiolitis. In our study, eight of the patients $(8 / 339,2.3 \%)$ in the study were co-infected with RSV and hRV, which was not found to be associated with a more severe clinical course than the other virus infected patients. No clear consensus on the effect of co-infection on disease severity is remained.

Respiratory viruses were detected positive more often in winter $(151,44.5 \%)$ and spring $(98,28.9 \%)$ than in autumn $(58,17.1 \%)$ and summer $(32,9.4 \%) \quad(p<0.01)$. Most studies have shown the same result in that epidemics of respiratory viruses have been observed in winter and early spring. ${ }^{36-38}$ RSV was seen mostly in winter $(52,34.4 \%)$ as known that cases tended to peak in winter in temperate climates ${ }^{12}$, 39. IFV was mostly seen in winter $(20,13.2 \%)$ especially in December. Gülen et al.12 showed that IFV was found most frequently in the November-December period in Turkey. Moreover in an other study from Turkey Çiçek et. ${ }^{40}$ al indicated that IFV was mostly seen from November to March. Our previous study in 2011-2012 influenza season showed that the first case of influenza B was detected in January, with a number of new cases peaking in March $^{16}$. In recent years IFV especially influenza B usually begin to appear between mid-winter and late-spring months in Turkey. ${ }^{41}$

Antibiotics were administered to three quarters of positive patients $(270 / 357 ; 75.7 \%)$ in our population. Although viruses are the most common cause of acute respiratory tract infections, the main etiological diagnosis is often missed and unnecessary or inappropriate antibiotic use is seen in more than $50 \%$ of acute respiratory tract infections worldwide ${ }^{11}$. This leads to the development of serious outcomes such as high resistance rates or multidrug resistance along with drug side effects in children with viral infectious. ${ }^{10,11}$

According to our data, $9.3 \%$ of our patients had bacteremia and respiratory viral infection at the same time. However we could not use bacterial respiratory tract culture tests because of the existence of unknown pathogens, poor accuracy and sensitivity. ${ }^{42}$ Also, we could not use bacterial molecular amplification tests which are highly sensitive, can provide results in hours but may distinguish colonization from infection. ${ }^{43}$ It is important to keep in mind that the most common pathogens causing bacterial pneumonia in childhood are part of the nasopharyngeal mucosal flora in healthy children. ${ }^{44}$

Clinical laboratories traditionally use methods such as direct fluorescent-antibody assay (DFA) and viral culture to detect respiratory viruses. Compared with such traditional methods, nucleic acid amplification tests show superiority in terms of sensitivity for the detection and spectrum of target viruses. In addition, the use of multiplex assays significantly reduces 
the hands-on time and cost compared to those for DFA and culture. The sensitivity of multiplex PCR assay method that was used in this study ranges $89.4-100 \%$ and specificity ranges $98.6-100 \% .{ }^{45}$ This method has different sensitivity and specificity for each virus such as the other PCR methods. ${ }^{44,45}$ In our study, we only used multiplex RT-PCR technique to identify respiratory tract viruses, thus we could not make a comparison with other diagnostic methods to investigate sensitivity and specificity.

There are some limitations to this study. One of the main limitations of this study is that it is a retrospective study so we could not obtain all the patients' clinical information. Due to the limited opportunities of our hospital, in some viral years we could do viral testing only on inpatients and in two different years we were not able to do testing to both inpatients and outpatients. Another limitation is that children with respiratory tract infections resulting from bacterial pathogens such as Streptoccus pneumoniae and Streptoccus pyogenes were not investigated in this study, which may have infected patients and affect at our clinical and laboratory parameters.

With an overall viral agent detection rate of $27.3 \%$, the findings of the present study suggest that other respiratory pathogens, whether viral or bacterial, may also lead to hospital visits due to respiratory tract symptoms in children. Also, it should be taken into account that each of the viral infections may appear in different ages of children, underlying diseases, clinical findings, physical examination, chest X-ray findings, clinical diagnosis and prognosis.

\section{REFERENCES}

1. Khabbaz R, Bell BP, Schuchat A, Ostroff SM, Moseley R, Levitt A, Hughes JM. Emerging and Reemerging Infectious Disease Threats. In: Mandell GL, Bennett JE, Dolin R, Blaser MJ (eds). Mandell, Douglas, and Bennett's Principles and Practice of Infectious Diseases (8th ed). Philadelphia; Pennsylvania: Churchill Livingstone Elsevier. 2015; 158-177.

2. h t t p : / / w w w. who.int//bullet in / volumes/86/5/07-048769/en/

3. Dierig A, Heron LG, Lambert SB, et al. Epidemiology of respiratory viral infections in children enrolled in a study of influenza vaccine effectiveness. Influenza Other Respir Viruses 2014; 8: 293-301.
4. Yin JK. Salkeld G, Lambert SB, et al. Estimates and determinants of economic impacts from influenza-like illnesses caused by respiratory viruses in Australian children attending childcare: A cohort study. Influenza Other Respir Viruses 2013; 7: 1103-1112.

5. Donowitz GR, Ellison RT. Acute Pneumonia, In Mandell GL, Bennett JE, Dolin R, Blaser MJ (eds). Mandell, Douglas, and Bennett's Principles and Practice of Infectious Diseases. (8th ed). Philadelphia; Pennsylvania: Churchill Livingstone Elsevier 2015; 823-846.

6. Turner BT, The Common Cold, In: Mandell GL, Bennett JE, Dolin R, Blaser MJ (eds). Mandell, Douglas, and Bennett's Principles and Practice of Infectious Diseases. (8th ed). Philadelphia; Pennsylvania: Churchill Livingstone Elsevier 2015; 748-752.

7. Van den Hoogen BG, de Jong JC, Groen J, et al. A newly discovered human pneumovirus isolated from young children with respiratory tract disease. Nat Med 2001; 7: 719-724.

8. Ksiazek TG, Erdman D, Goldsmith CS, et al; SARS Working Group. A novel coronavirus associated with severe acute respiratory syndrome. N Engl J Med 2003; 348: 1953-1966.

9. Sloots TP, Whiley DM, Lambert SB, Nissen MD Emerging respiratory agents: New viruses for old diseases? J Clin Virol 2008; 42: 233-243.

10. Tregoning JS, Schwarze J. Respiratory viral infections in infants: Causes, clinical symptoms, virology and immunology. Clin Microbiol Rev 2010; 23: 74-98.

11. Zhang C, Zhu N, Xie Z, et al. Viral etiology and clinical profiles of children with severe acute respiratory infections in China. PloS One 2013; 8:e72606.

12. Gülen F, Yıldız B, Çiçek C, Demir E, Tanaç R. Ten year retrospective evaluation of the seasonal distribution of agent viruses in childhood respiratory tract infections. Turk Pediatri Ars 2014; 49: 42-46.

13. Hatipoğlu N, Somer A, Badur S, et al. Viral etiology in hospitalized children with acute lower respiratory tract infections. Turk J Pediatr 2011; 53: 508-516.

14. Bicer S, Giray T, Çöl D, Erdağ GÇ, et al. Virological and clinical characterizations of respiratory infections in hospitalized children. Ital J Pediatr 2013; 39: 22.

15. https://en.wikipedia.org/wiki/Ankara

16. Karadag-Oncel E, Ciblak MA, Ozsurekci Y, Badur S, Ceyhan M. Viral etiology of influenza-like illnesses during the influenza season between December 2011 and April 2012. J Med Virol 2014; 86: 865-871.

17. Ecochard-Dugelay E, Beliah M, Boisson C, et al. Impact of chest radiography for children with lower respiratory tract infection: A propensity score approach._PLoS One. 2014; 9: e96189.

18. Miller EK, Gebretsadik T, Carroll KN, et al. Viral etiologies of infant bronchiolitis, croup and upper respiratory illness during 4 consecutive years. Pediatr Infect Dis J 2013; 32: 950-955.

19. Definition of acute and chronic respiratory failure: https://acdis.org/system/files/resources/35450\%20 Pediatric\%20Respiratory\%20Failure\%20White\%20 Paper.pdf 
20. Beka H, Kilic A, Unuvar E, et al. Frequency of common viruses in etiology of acute respiratory tract infections. Indian J Pediatr 2013; 80: 91-96.

21. Dut R, Kocagöz S. Clinical signs and diagnostic tests in acute respiratory infections. Indian J Pediatr 2016; 83: $380-385$

22. Dawson-Caswell M, Muncie HL Jr. Respiratory syncytial virus infection in children. Am Fam Physician 2011; 83: $141-146$.

23. Cai XY, Wang Q, Lin GY, et al. Respiratory virus infections among children in South China. J Med Virol 2014; 86: 1249-1255.

24. Leung TF, Lam DS, Miu TY, et al; Hong Kong Society of Paediatric Respirology (HKSPR) RSV Concern Group. Epidemiology and risk factors for severe respiratory syncytial virus infections requiring pediatric intensive care admission in Hong Kong children. Infection 2014; 42: $343-350$

25. Knudson CJ, Varga SM. The relationship between respiratory syncytial virus and asthma. Vet Pathol 2015; 52: 97-106.

26. Wang H, Zheng Y, Deng J, et al. Prevalence of respiratory viruses among children hospitalized from respiratory infections in Shenzhen, China. Virol J 2016; 13: 39 .

27. Liu CY, Xiao Y, Xie ZD, et al. Viral etiology of acute respiratory tract infection among pediatric inpatients and outpatients from 2010 to 2012 in Beijing, China. Zhonghua Er Ke Za Zhi 2013; 51: 255-259.

28. Emukule GO, Khagayi S, McMorrow ML, et al. The burden of influenza and RSV among inpatients and outpatients in rural western Kenya, 2009-2012. PLoS One 2014; 9: e105543.

29. Hall CB, Weinberg GA, Iwane MK, et al. The burden of respiratory syncytial virus infection in young children. N Engl J Med 2009; 360: 588-598.

30. Asner SA, Rose W, Petrich A, Richardson S, Tran DJ. Is virus coinfection a predictor of severity in children with viral respiratory infections? Clin Microbiol Infect 2015; 21: 264.e1-e6.

31. Echavarría M. Adenoviruses in immunocompromised hosts. Clin Microbiol Rev 2008; 21: 704-715.

32. Jacobs SE, Lamson DM, Soave R, et al. Clinical and molecular epidemiology of human rhinovirus infections in patients with hematologic malignancy. J Clin Virol 2015; 71: 51-58.

33. Martínez-Roig A, Salvadó M, Caballero-Rabasco MA, Sánchez-Buenavida A, López-Segura N, Bonet-Alcaina M. Viral coinfection in childhood respiratory tract infections. Arch Bronconeumol 2015; 51 :5-9.
34. Semple MG, Cowell A, Dove W, et al. Dual infection of infants by human metapneumovirus and human respiratory syncytial virus is strongly associated with severe bronchiolitis. J Infect Dis 2005; 191: 382-386.

35. Richard N, Komurian-Pradel F, Javouhey E, et al. The impact of dual viral infection in infants admitted to a pediatric intensive care unit associated with severe bronchiolitis. Pediatr Infect Dis J 2008; 27: 213-217.

36. Monto AS. Epidemiology of viral respiratory infections. Am J Med 2002; 112: 4S-12S.

37. Heikkinen T, Osterback R, Peltola V, Jartti T, Vainionpää R. Human metapneumovirus infections in children. Emerg Infect Dis 2008; 14: 101-106.

38. Iwane MK, Edwards KM, Szilagyi PG, et al; New Vaccine Surveillance Network. Population-based surveillance for hospitalizations associated with respiratory syncytial virus, influenza virus, and parainfluenza viruses among young children. Pediatrics 2004; 113: 1758-1764.

39. Yusuf S, Piedimonte G, Auais A, et al. The relationship of meteorological conditions to the epidemic activity of respiratory syncytial virus. Epidemiol Infect 2007; 135: 1077-1090.

40. Çiçek C, Arslan A, Karakuş HS, et al. Prevalence and seasonal distribution of respiratory viruses in patients with acute respiratory tract infections, 2002-2014. Microbiyol Bul 2015; 49: 188-200.

41. http://www.thsk.gov.tr/haberler/haftalik-influenza-gripsurveyans-raporu.html

42. Zumla A, Al-Tawfiq JA, Enne VI et al. Rapid point of care diagnostic tests for viral and bacterial respiratory tract infections--needs, advances, and future prospects. Lancet Infect Dis 2014; 14: 1123-1135.

43. Tenover FC. Developing molecular amplification methods for rapid diagnosis of respiratory tract infections caused by bacterial pathogens. Clin Infect Dis 2011; 52(Suppl 4): S338-S345.

44. Krause JC, Panning M, Hengel H, Henneke P. The role of multiplex PCR in respiratory tract infections in children. Dtsch Arztebl Int 2014; 111: 639-645.

45. Kim HK, Oh SH, Yun KA, Sung H, Kim MN Comparison of anyplex II RV16 with the xTAG respiratory viral panel and seeplex RV15 for detection of respiratory viruses. J Clin Microbiol 2013; 51: 11371141. 